\title{
A wide diversity of zoonotic intestinal parasites infects urban and rural dogs in Neuquén, Patagonia, Argentina
}

\author{
Silvia Viviana Soriano ${ }^{\mathrm{a}, *}$, Nora Beatriz Pierangeli ${ }^{\mathrm{a}}$, Irene Roccia ${ }^{\mathrm{b}}$, \\ Hector Fabián Jesus Bergagna ${ }^{c}$, Lorena Evelina Lazzarini ${ }^{a}$, Alejandra Celescinco ${ }^{c}$ \\ Mónica Susana Saiz ${ }^{a}$, Alejandra Kossman ${ }^{a}$, Pablo Adrián Contreras ${ }^{a}$, Cecilia Arias ${ }^{a}$, \\ Juan Angel Basualdo ${ }^{\mathrm{d}}$ \\ ${ }^{a}$ Cátedra de Microbiología y Parasitología, Escuela de Medicina, Universidad Nacional del Comahue, Buenos Aires 1400, J.B. Alberdi 136, (8300) Neuquén, Argentina \\ ${ }^{\mathrm{b}}$ Departamento de Zoonosis, Subsecretaria de Salud, Provincia de Neuquén, Fotheringham 121, (8300) Neuquén, Argentina \\ ${ }^{\mathrm{c}}$ Dirección de Zoonosis y Vectores, Municipalidad de Neuquén, Av. Argentina 307, (8300) Neuquén, Argentina

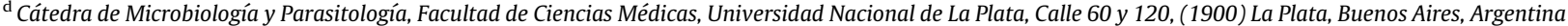

\section{A R T I C L E I N F O}

Article history:

Received 16 April 2009

Received in revised form 20 August 2009

Accepted 27 September 2009

\section{Keywords:}

Dog

Parasitic agents

Argentina

Rural

Urban

Zoonoses

\begin{abstract}
A B S T R A C T
The presence of parasites was investigated by the examination of 1944 dog faecal samples collected from urban $(n=646)$ and rural $(n=1298)$ areas of the province of Neuquén, Patagonia, Argentina. Parasitic agents (PA) were found in $37.86 \%$ of samples. A total of 15 different PA were detected, including Toxocara canis (16.35\%), Taenia spp./Echinococcus spp. (12.65\%), Trichuris vulpis (6.06\%), Giardia spp. (1.29\%), Toxascaris leonina $(0.56 \%)$, Ancylostoma caninum (0.41\%), Dipylidium caninum (0.31\%), Diphyllobothrium spp. (0.10\%), among others. Several of these PA are recognized as zoonotic agents. Therefore, the results of this investigation revealed that local population is exposed to a broad spectrum of zoonotic parasites by means of environmental contamination with dog faeces. Prevalence of PA was slightly higher in rural (40.06\%) than in urban (33.44\%) locations. Distribution of groups of PA (cestodes, nematodes, and protozoa) showed statistical differences between both habitats. Prevalence of cestodes (18.18\%) and protozoa (11.86\%) was significantly higher in the rural environment than in urban areas and nematodes $(29.10 \%)$ were more frequent in urban locations. Infection of dogs with Linguatula serrata and Cryptosporidium sp. was demonstrated for the first time in Neuquén. Rural dogs of the study area are under hydatic disease control program, which includes treatment with praziquantel every 6 weeks; thus, the finding of high level of cestode infection in these areas is of great relevance. The epidemiology of zoonotic parasitic infections in urban and rural dogs showed different patterns and, in consequence, different control measurements should be applied in each location.
\end{abstract}

(c) 2009 Elsevier B.V. All rights reserved.

\section{Introduction}

Several studies performed throughout the world have demonstrated that dogs can play an important role in the transmission of zoonotic parasites. Dogs are definitive

\footnotetext{
* Corresponding author. Tel.: +54 299443 0820; fax: +54 2994430820. E-mail address: vivianasoriano@jetband.com.ar (S.V. Soriano).
}

hosts for several helminths and protozoan with zoonotic potential like Taenia spp./Echinococcus spp., Toxocara canis, Dipylidium caninum, Ancylostoma spp., Giardia spp., or Cryptosporidium sp. Contamination of urban public areas (parks, squares, and streets) with dog faeces harbouring infective parasitic forms is frequent in many countries representing a high risk of infection for the people living in those areas and therefore constituting a serious public health problem. In rural areas, close contact between dogs 
and humans is part of natural living conditions especially in regions where livestock raising is of economic importance (Pierangeli et al., 2007). In consequence, rural populations are also at risk of acquiring zoonotic diseases transmitted by dogs.

Understanding the epidemiology of zoonotic parasitic infections is important to minimize the risks to humans (Dubná et al., 2007). Since there are no published data about the epidemiology of parasites present in canine faeces in the province of Neuquén, Argentine Patagonia, the aims of the present work were to determine the presence of PA in faeces of urban (owned and stray) and rural dogs; to compare the epidemiology of both populations and to assess potential risk for human infection with dog transmitted parasites.

\section{Materials and methods}

\subsection{Study area and design}

The province of Neuquén is located in the north of the Argentine Patagonia region, with an area of $94,078 \mathrm{~km}^{2}$ (Fig. 1). The total population estimated in 2004 was 502,268 inhabitants, 201,202 of whom live in the city of Neuquén (capital district) and its periphery. The rest of the population is distributed in small cities and in rural areas. Rural population lives in small communities and raise goats or less frequently sheep for subsistence, mostly under a transhumant model of production. Different climatic and geographic conditions are present. The weather is continental semi-arid, with warm dry summers and cold winters that have a larger relative environmental humidity. Hydatic disease is endemic in Neuquén and the province carries out a control program that includes periodic administration of praziquantel $(5 \mathrm{mg} / \mathrm{kg}$ ) to rural dogs every 6 weeks. To achieve the objectives of the present work a prospective, observational and analytical study was carried out between June 2005 and October 2008.

\subsection{Source of samples}

During the study period a total of 1944 samples of fresh dog faeces were collected from streets, parks and squares in urban locations as well as from the peridomicile and interior of farms in rural areas. Of those samples, 646 were obtained from urban areas of Neuquén city and Chos Malal

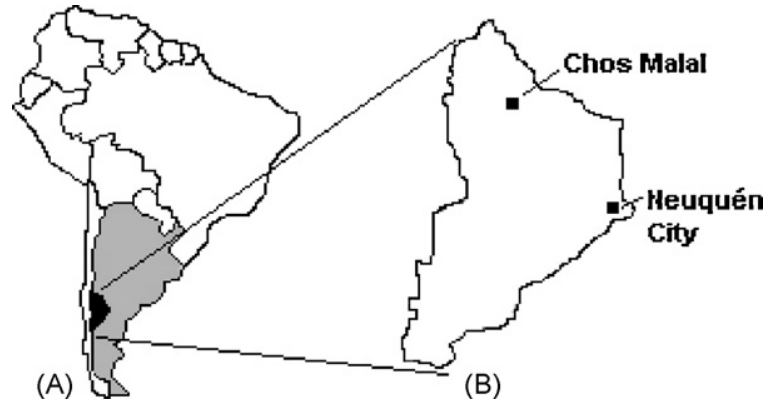

Fig. 1. Geographic location. (A) Argentina in South America and Neuquén in Argentina. (B) Location of Neuquén and Chos Malal cities. (a small city located in the north of the province) and 1298 from rural districts.

\subsection{Parasitological procedures}

Faecal samples were collected in 5\% formaldehyde and processed by flotation and sedimentation conventional methods. Each sample was microscopically examined at $100 \times$ and $400 \times$ amplifications. Identification of PA was performed by morphological characteristics. In addition, 100 samples from Neuquén city were screened for Cryptosporidium sp. by means of a modified Ziehl Neelsen method (standard technique without heating). A sample was recorded as positive if at least one parasitic form was observed by any method.

\subsection{Data analysis}

Data analysis was performed using EpiInfo2000 Software (Centers for Disease Control, Atlanta, USA). Differences between groups were compared by the Chi-square $\left(\chi^{2}\right)$ test and considered statistically significant when $p<0.05$. For statistical analysis of the data, samples were grouped by location into rural or urban. The Fager index was calculated to measure the affinity between pairs of associated species (Fager, 1957). The degree of resemblance between the species present in rural and urban locations was evaluated by the Sorensen coefficient of similarity (Brower and Zar, 1977). Three indexes were calculated to compare the diversity of species present in each location: the Shannon-Weaver index of specific diversity, the absolute diversity index and the equitability index (Morales and Arelis Pino, 1987).

\section{Results}

The overall prevalence of PA was $37.86 \%$ among the 1944 faecal samples analyzed. The most frequently observed parasite was T. canis (16.35\%) followed by Taenia spp./Echinococcus spp. (12.65\%), Trichuris vulpis (6.06\%) and others with minor percentages. The general and relative prevalences of each parasite are shown in Table 1. Multiple infections were remarkably less frequent (22.82\%) than infections with a single parasite (77.18\%).

General prevalence of parasites showed a slight significant difference between rural (40.06\%) and urban (33.44\%) dog populations. However, when the distribution of groups of parasites (nematodes, cestodes, and protozoa) in each habitat was analyzed, higher statistical differences in general and relative prevalences were observed (Table 2). Values of the Shannon-Weaver specific diversity index were 2.44 for rural and 1.95 for urban samples. The results for absolute diversity were 3.70 and 3.32 and for the equitability index 0.65 and 0.58 for rural and urban samples, respectively, in each case. The Sorensen coefficient of similarity between both locations was 0.78 .

Results of the analysis performed at the genera-species level are also shown in Table 2. Single infection was predominant both in rural and urban dogs. The distribution of samples by number of associated parasite genera is shown in Table 3. When present, the most frequent associations 
Table 1

General and relative prevalence of parasitic agents in dog faeces from Neuquén province.

\begin{tabular}{|c|c|c|c|}
\hline Parasites & Number of positive samples & General prevalence $^{a}(n=1944)(\%)$ & Relative prevalence $^{\mathrm{b}}(n=736)(\%)$ \\
\hline \multicolumn{4}{|l|}{ Nematodes } \\
\hline Toxocara canis & 318 & 16.35 & 43.20 \\
\hline Trichuris vulpis & 118 & 6.06 & 16.03 \\
\hline Toxascaris leonina & 11 & 0.56 & 1.49 \\
\hline Ancylostoma caninum & 8 & 0.41 & 1.09 \\
\hline Capillaria spp. & 2 & 0.10 & 0.27 \\
\hline Total $^{\mathrm{c}}$ & 441 & 22.68 & 57.61 \\
\hline \multicolumn{4}{|l|}{ Cestodes } \\
\hline Taenia spp./Echinococcus spp. & 246 & 12.65 & 33.42 \\
\hline Dipylidium caninum & 6 & 0.31 & 0.81 \\
\hline Diphyllobothrium spp. & 2 & 0.10 & 0.27 \\
\hline Total $^{\mathrm{c}}$ & 254 & 13.6 & 33.51 \\
\hline \multicolumn{4}{|l|}{ Protozoa } \\
\hline Sarcocystis spp. & 110 & 5.65 & 14.94 \\
\hline Entamoeba spp. & 32 & 1.65 & 4.35 \\
\hline Giardia spp. & 25 & 1.29 & 3.40 \\
\hline Isospora spp. & 19 & 0.98 & 2.58 \\
\hline Total $^{\mathrm{c}}$ & 172 & 8.85 & 23.37 \\
\hline \multicolumn{4}{|l|}{ Pentastomids } \\
\hline Linguatula serrata & 17 & 0.87 & 2.31 \\
\hline \multicolumn{4}{|l|}{ Acanthocephalans } \\
\hline Oncicola canis & 4 & 0.21 & 0.54 \\
\hline
\end{tabular}

detected were T. canis-Taenia spp./Echinococcus spp. in rural areas (29.50\% of biparasitated samples) and T. canis-Trichuris spp. in urban dogs (56\% of samples harbouring 2 parasites). However, the Fager index values for these associations were 0.14 and 0.20 , respectively, indicating that affinity between pairs of species was not significant.

Cryptosporidium sp. was observed in 1 of 100 urban samples. Because of the small number of samples in which this parasite was investigated, its presence is not shown in Tables 1 and 2 .

\section{Discussion}

Several surveys have been carried out in different countries to determine the prevalence of intestinal parasites among dogs, with heterogeneous results. In areas where environmental and climatic characteristics were favorable to parasite transmission and/or poor socioeconomic conditions were present, high rates of infection were detected (Traub et al., 2002; Wang et al., 2006). In contrast, surveys conducted in urban locations with adequate sanitary conditions revealed prevalences of intestinal parasites below 20\% (Sager et al., 2006; Dubná et al., 2007). In Argentina, prevalences of $46.6 \%$ of PA were found in Chubut (Sanchez Thevenet et al., 2003) and helminths were present in $74 \%$ of dog faeces in Salta (Taranto et al., 2000), among other reports.

The overall prevalence of PA found in our investigation was $37.86 \%$, showing that the presence of PA in dog faeces from Neuquén is situated at an intermediate level. This result can be explained taking into account that previous reports of intestinal parasites in children (Soriano et al.,
2001) and soil (Pierangeli et al., 2003) of Neuquén have demonstrated that geographical and climatic characteristics of this Patagonic region are slightly favorable to parasite transmission.

T. canis was the most common parasite, followed by Taenia spp./Echinococcus spp. These results agree with the findings of Sanchez Thevenet et al. (2003) but differ with other reports in which, although $T$. canis showed to be the most prevalent, taenidae were of less relevance (Taranto et al., 2000; Sager et al., 2006).

We were able to determine the presence of a wide diversity of parasites among the samples analyzed, including 5 nematodes, 3 cestodes, 5 protozoa, 1 pentastomid and 1 acanthocephalan. The high value obtained for the Sorensen coefficient of similarity indicated that most of these species were present in both urban and rural locations, whereas the application of the equitability index demonstrated a great dominance of some species over others in both cases.

Several of the PA detected in dog faeces from Neuquén are recognized as potentially zoonotic, including $T$. canis, Toxascaris leonina, Ancylostoma caninum, Diphyllobothrium spp. or D. caninum. Taenia spp./Echinococcus spp. eggs, indistinguishable between them by coprological examination, showed a general prevalence of $12.65 \%$. This fact poses a severe threat to human health as Echinococcus spp. is the causative agent of cystic echinococcosis, an endemic disease in the patagonic region. Although the importance of dogs as transmitters of Giardia spp. to humans has been controversial in the past, recent molecular studies have demonstrated that some Giardia genotypes can be infective for both hosts (Minvielle et al., 2008). 
Table 2

General and relative prevalence of parasitic agents in rural and urban dog faeces from Neuquén province.

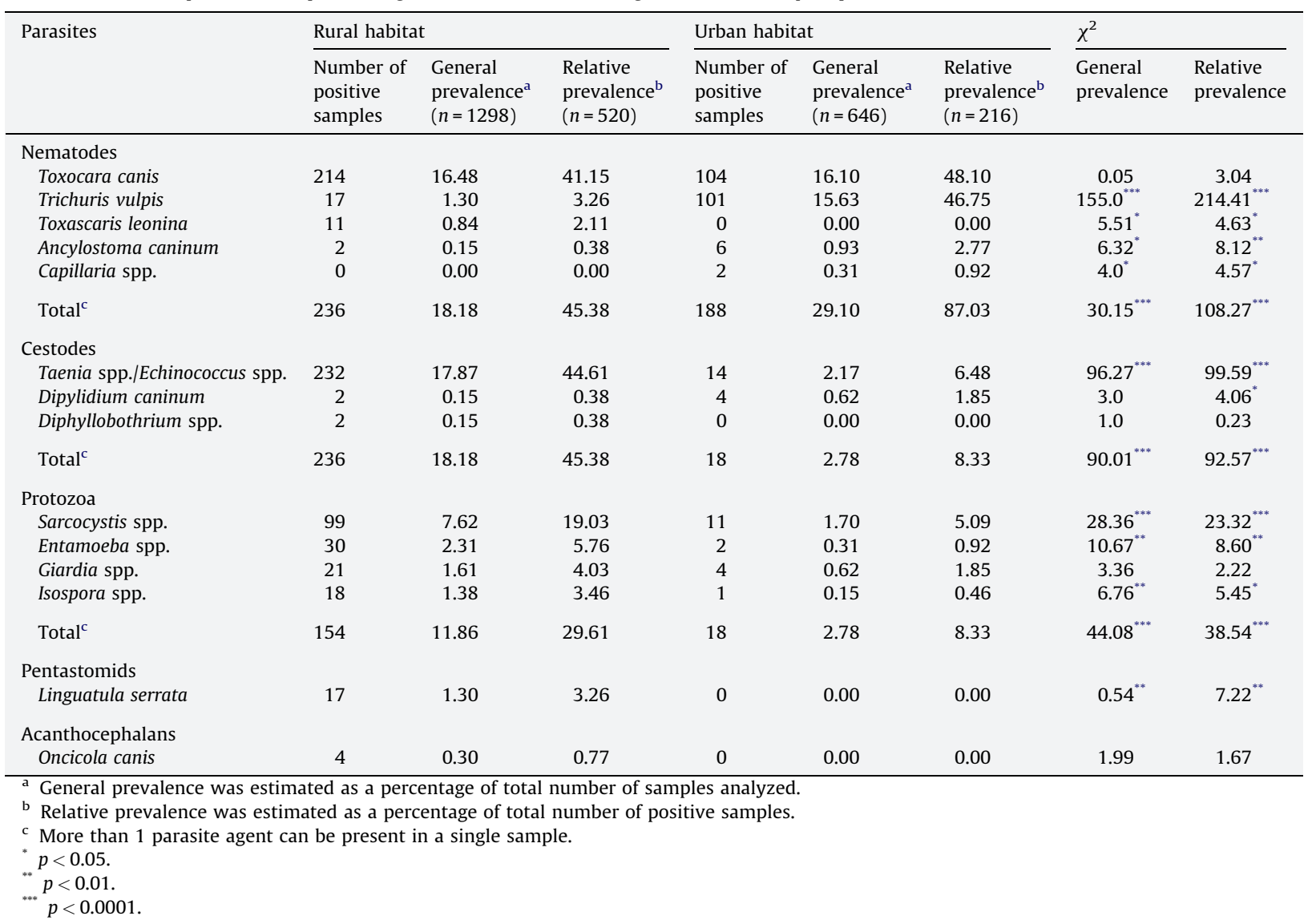

This investigation is the first report of the presence of Cryptosporidium sp. in faeces from urban dogs of Neuquén and of eggs of Linguatula serrata in dogs from Argentina. Dogs are definitive hosts for this pentastomid whose adult forms are found mostly in the nasal airways. Eggs can reach the canine intestine by deglution and be eliminated to the environment by faecal deposits. Humans act as intermediate hosts for this parasite after the ingestion of infective eggs, developing visceral pentastomiasis. Higher prevalences of PA in rural than in urban dogs were observed in published investigations in which these populations were compared (Martinez Moreno et al., 2007; Dubná et al., 2007). However, only a slight statistically significant difference in general prevalence of PA among both populations was found in the current study. To analyze these results, 2 points must be taken into account: first, rural dogs in the province of Neuquén are under periodic treatment with praziquantel every 6 weeks. Second, capture and euthanasia of stray dogs is forbidden in the whole province; therefore, this dog population has considerably increased in the last years, especially in urban areas. Since there are no regulations concerning canine faecal deposits in public areas, contamination with dog faeces is highly frequent in urban locations, favouring parasite transmission.

Table 3

Distribution of samples by number of associated parasite genera.

\begin{tabular}{|c|c|c|c|c|c|c|}
\hline \multirow[t]{2}{*}{ Number of parasites } & \multicolumn{2}{|c|}{ Rural } & \multicolumn{2}{|c|}{ Urban } & \multirow[t]{2}{*}{$\chi^{2}$} & \multirow[t]{2}{*}{$p$} \\
\hline & $N$ & $\%$ & $N$ & $\%$ & & \\
\hline 1 & 386 & 74.23 & 181 & 83.79 & 7.88 & $<0.01$ \\
\hline 2 & 112 & 21.53 & 35 & 16.20 & 2.71 & 0.09 \\
\hline 3 & 21 & 4.03 & 0 & 0.00 & - & - \\
\hline 4 & 1 & 0.19 & 0 & 0.00 & - & - \\
\hline Total & 520 & 100 & 216 & 100 & & \\
\hline
\end{tabular}

$N$ : number of samples. 
Cestodes were the most frequent parasites found in the rural environment where Taenia spp./Echinococcus sp. showed to be present in $44.61 \%$ of positive samples, whereas relative prevalence in urban areas was $6.48 \%$. These results strongly suggests that, despite the undergoing control program, dogs in rural areas still have easy access to raw offal and/or an important number of rural dogs are out of antiparasitic treatment, probably due to the fact that since 1990 praziquantel is provided by the Province Public Health System but dosing is under owner's responsibility and no surveillance of fulfilment of program guidelines is carried out.

Although general prevalence of PA in dogs of Neuquén appears to be at intermediate level, the people living in this region are exposed to a broad spectrum of zoonotic parasites by means of environmental contamination with dog faeces. The epidemiology of zoonotic parasitic infections in urban and rural dogs showed different patterns and, in consequence, different control measurements should be applied in each location. Efforts should be made to improve surveillance and fulfilment of hydatic disease control program in rural areas.

\section{Conflict of interest}

All authors declare that there are no financial or personal relationships that could inappropriately influence their contributions to this investigation.

\section{Acknowledgements}

The authors are grateful to Hermosina Ruth Astete for efficient technical assistance and to Prof. Luciana Di Pascuale for language revision. We are also thankful to Méd. Vet. Marcelo Infante, Méd. Vet. Claudio Brusoni, Juan Carlos Arias and technicians of the Environmental and Zoonosis Department of the Province of Neuquén for the collection of samples from rural areas and Chos Malal. This study was supported by grant 04/N005 from the Research Department of Universidad Nacional del Comahue.

\section{References}

Brower, J., Zar, J. (Eds.), 1977. Field and Laboratory Methods for General Ecology. WM Brown Company Publishers, USA, 194 pp.

Dubná, S., Langrová, I., Nápravník, J., Jankovská, I., Vadlejch, J., Pekár, S., Fechtner, J., 2007. The prevalence of intestinal parasites in dogs from Prague, rural areas, and shelters of the Czech Republic. Vet. Parasitol. $145,120-128$.

Fager, E., 1957. Determination and analysis of recurrent groups. Ecology 38, 586-595.

Martinez Moreno, F.J., Hernández, S., López Cobos, E., Becerra, C., Acosta, I., Martínez Moreno, A., 2007. Estimation of canine intestinal parasites in Córdoba (Spain) and their risk to public health. Vet. Parasitol. 143, 7-13.

Minvielle, M.C., Molina, N.B., Polverino, D., Basualdo, J.A., 2008. First genotyping of Giardia lamblia from human and animal feces in Argentina, South America. Mem. Inst. Oswaldo Cruz 103 (1), 98-103.

Morales, G., Arelis Pino, L. (Eds.), 1987. Parasitología cuantitativa. Acta Cient. Venez, Venezuela, $132 \mathrm{pp}$.

Pierangeli, N.B., Giayetto, A.L., Manacorda, A.M., Barbieri, L.M., Soriano, S.V., Veronesi, A., Pesani, B.C., Minvielle, M.C., Basualdo, J.A., 2003. Estacionalidad de parásitos intestinales en suelos periurbanos de la ciudad de Neuquén, Patagonia, Argentina. Trop. Med. Intern. Health 8 (3), 259-263.

Pierangeli, N.B., Soriano, S.V., Roccia, I., Giménez, J., Lazzarini, L.E., Grenóvero, M.S., Menestrina, C., Basualdo, J.A., 2007. Heterogeneous distribution of human cystic echinococcosis after a long-term control program in Neuquén, Patagonia Argentina. Parasitol. Int. 56, 149-155.

Sager, H., Steiner Moret, Ch., Grimm, F., Deplazes, P., Doherr, M.G., Gottstein, B., 2006. Coprological study on intestinal helminthes in Swiss dogs: temporal aspects of anthelminthic treatment. Parasitol. Res. 98, 333-338.

Sanchez Thevenet, P., Jensen, O., Mellado, I., Torrecillas, C., Raso, S., Flores, M.E., Minvielle, M.C., Basualdo, J.A., 2003. Presence and persistence of intestinal parasites in canine fecal material collected from the environment in the Province of Chubut, Argentine Patagonia. Vet. Parasitol. 117, 263-269.

Soriano, S.V., Barbieri, L.M., Pierangeli, N.B., Giayetto, A.L., Manacorda, A.M., Castronovo, E., Pesani, B.C., Minvielle, M.C., Basualdo, J.A., 2001. Intestinal parasites and the environment: frequency of intestinal parasites in children of Neuquén, Patagonia, Argentina. Rev. Latinoam. Microbiol. 43, 96-101.

Taranto, N.J., Passamonte, L., Marinconz, R., De Marzi, M.C., Cajal, S.P., Malchiodi, E.L., 2000. Parasitosis zoonoticas transmitidas por perros en el Chaco Salteño. Medicina (B Aires) 60, 217-220.

Traub, R.J., Robertson, I.D., Irving, P., Mencke, N., Thompson, R.C.A., 2002. The role of dogs in transmission of gastrointestinal parasites in a remote tea-growing community in northeastern India. Am. J. Trop. Med. Hyg. 67 (5), 539-545.

Wang, C.R., Qiu, J.H., Zhao, J.P., Xu, L.M., Yu, W.C., Zhu, X.Q., 2006. Prevalence of helminthes in adult dogs in Heilongjiang Province, the People's Republic of China. Parasitol. Res. 99, 627-630. 